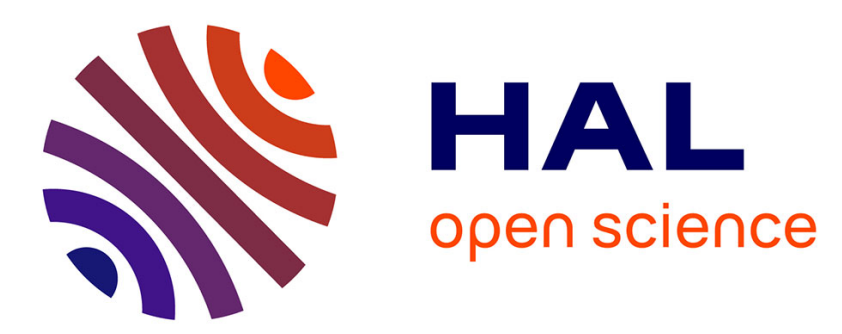

\title{
Studying the Effects of Visual Movement on Creativity
} Sylvain Fleury, Aurélien Agnes, Rishi Vanukuru, Emma Goumillout, Nicolas Delcombel, Simon Richir

\section{To cite this version:}

Sylvain Fleury, Aurélien Agnes, Rishi Vanukuru, Emma Goumillout, Nicolas Delcombel, et al.. Studying the Effects of Visual Movement on Creativity. Thinking Skills and Creativity, 2020, pp.9. 10.1016/j.tsc.2020.100661 . hal-02546539

\section{HAL Id: hal-02546539 \\ https://hal.science/hal-02546539}

Submitted on 12 May 2020

HAL is a multi-disciplinary open access archive for the deposit and dissemination of scientific research documents, whether they are published or not. The documents may come from teaching and research institutions in France or abroad, or from public or private research centers.
L'archive ouverte pluridisciplinaire HAL, est destinée au dépôt et à la diffusion de documents scientifiques de niveau recherche, publiés ou non, émanant des établissements d'enseignement et de recherche français ou étrangers, des laboratoires publics ou privés. 


\section{Studying the Effects of Visual Movement on Creativity}

Sylvain Fleury,

Arts et Métiers Sciences et Technologies, LAMPA, HESAM Université, F-53810 Changé, France

Sylvain.fleury@ensam.eu

Aurélien Agnès,

Arts et Métiers Sciences et Technologies, LAMPA, HESAM Université, F-53810 Changé, France

Rishi Vanukuru,

IDC School of Design, IIT Bombay

Emma Goumillout,

École nationale supérieure de cognitique

Nicolas Delcombel,

École nationale supérieure de cognitique

\section{Simon Richir}

Arts et Métiers Sciences et Technologies, LAMPA, HESAM Université, F-53810 Changé, France

\section{Abstract}

Many studies have shown that physical activity, especially walking, tends to stimulate certain cognitive functions, including divergent creativity. The objective of this study was to understand whether some of this gain comes from the perception of movement, and not merely physical activity itself. 32 participants carried out divergent and convergent creativity tasks in a virtual reality environment consisting of a train inside a tunnel, while wearing a HeadMounted-Display (HMD). For half of the participants, the virtual train was running, and they could therefore see tunnel lamps passing by through the windows. For the other half, the train was stationary. The results of this study indicate that participants perform better at tasks that require divergent creativity when the virtual environment is moving than when it is at a standstill. These results lead to recommendations for the design of tools and environments for meetings and creativity workshops.

Keywords: Perceptive Movement, Divergent Creativity, Virtual Reality, Creativity Stimulation, Digital Tools for Creativity

\section{Introduction}

Numerous writers and philosophers have put forth and supported the idea that walking makes thinking easier. It is common to observe people who cannot make a phone call without walking back and forth. One explanation for this is that walking speeds up the heartbeat, causing more blood and oxygen to flow to muscles and organs, including the brain. Walking is also said to be a way of connecting the rhythm of our body to our mental state. We do not make a conscious effort when we walk, therefore leaving the mind available for more creative thinking.

The question of the effects of body postures and physical activity on intellectual performance of different kinds has long been the subject of studies in the field of management and 
organization of work spaces. Non-sedentary organisation of work spaces, i.e. the absence of offices allocated to a particular employee, has two main consequences. The first one is the decrease of territoriality, leading employees to make better use of $t$ he whole premises and move around more. The second effect is an increase in the level of physiological arousal that promotes intellectual work (Knight \& Baer, 2014).

The classic posture in office work is a sitting one. Time spent sitting is associated with negative health effects, and this has been motivating more and more people to adopt standing workstations. At present, the effects of this type of arrangement on cognitive performance are not entirely clear. In a study by Finch, Tomiyama \& Ward (2017), standing had no effect on text comprehension or performance on a creative task compared to sitting. The only difference between the two conditions in this study was the commitment to the task. Participants performing these tasks while standing showed more interest and enthusiasm. In research by Gilson et al (2017), participants were asked to perform cognitive tasks while sitting, standing with a higher desk, or standing while walking on a treadmill. The results indicate that standing allows for better regulation of stress levels (measured here by the cortisol level in saliva), and better allocation of attentional resources. Walking, on the other hand, does not make a difference on these variables compared to standing without movement in this study.

However, other studies show that similar to running and dancing (e.g. Gondola, 1986, 1987), walking can have positive effects on creativity (Schaefer et al. 2010; Weuve et al. 2004). These effects may be explained by a decrease in stress hormones in the brain (Salmon, 2001), but also by a decrease in blood pressure and oxygen supply to the brain that facilitates mental associations (O'Mara, 2019). Zhou, Zhang, Hommel and Zhang (2017) compared divergent creative performance for people sitting, standing still, and walking. Standing led to better performance compared to sitting, and walking also improved performance in the study. The authors consider that more divergent thinking is displayed when the corresponding physical activity requires more control resources. Conversely, performance in some cognitive tasks like subtraction or counting phonemes in words tends to be degraded when they are conducted while walking (Srygley et al., 2009).

In a recent study by Frith and Loprinzi (2018), participants were asked to perform divergent and convergent thinking tasks by walking on a treadmill, listening to music, or just sitting. Walking on the treadmill had no significant effect on the different indicators of divergent creativity, which is inconsistent with the study by Oppezzo and Schwartz (2014), but also with Abdullah, Czerwinski, Mark and Johns (2016), for whom walking on the treadmill improves divergent but not convergent thinking. The main constant in the literature is the lack of effect of physical activity on convergent thinking. It seems that walking can have a positive effect on divergent creativity, although this does not seem to occur in all contexts. A particularly comprehensive study on the subject has been carried out by Oppezzo and Schwartz (2014). It shows that walking improves divergent thinking (measured by Guiford's alternate uses test; Guilford, 1960), but not convergent thinking (measured by Barron's symbolic equivalence test; Barron, 1963). Experimental sessions lasted a few minutes and the authors found that the positive effects of walking were maintained for the next few minutes even if the participant sat down. Furthermore, this research also shows that divergent thinking performance is higher for participants pushed in a wheelchair outside than for participants sitting in a stationary chair inside. However, it is not clear from the study whether this difference is due to being in motion and therefore seeing the scenery moving, or being in an outdoor environment. The effect of physical activity alone on divergent creativity is noted because the participants are indoors. Similarly, when the experience is replicated while walking outside, the same differences appear. Finally, an experiment was conducted to study the effect of sitting or 
standing and the effect of being indoors or outdoors, using another measure of creativity. In this experiment, all cases of walking had an effect on creativity, and being outside had an effect on the "novelty" of the ideas proposed. However, two aspects of this analysis are missing in order to provide a more complete understanding of the effect of physical activity. First, there was no comparison of the results between sitting outside and inside, and walking outside and inside. Indeed, the creativity scores all appear to be higher when walking outside than when walking inside. Secondly, the variable "dynamic outdoors - sitting" is significantly different from "sitting indoors", as the participants are still moving. Thus, they are not comparing two immobile positions, but two conditions in which there is no physical activity, without isolating the effect of movement as perceived by the participants. This perception of movement could be of two types: it could be the visual perception of movement, or it could be the physical sensation of being moved. In the present research, we have chosen to isolate specifically the effect of visually perceived movement on creativity.

This idea that visual movement can have an impact on certain cognitive components and more specifically creative capabilities has not been demonstrated in the literature to the best of our knowledge, although some research projects in the field of neuroscience do provide indications of the effect. The cerebellum is particularly known for its role in motor functions. However, it is also involved in visual perceptive treatments (Baumann et al., 2015), particularly visual perception of movement (Nawrot \& Rizzo, 1995) and visual attention (Brissenden \& Somers, 2019). The cerebellum is also engaged in cognitive functions such as working memory (Küper et al., 2016). Finally, the cerebellum is involved in various creativity tasks (Levy, Urbanski, Josse \& Volle, 2013). In particular, it is more engaged in so-called idea generation tasks, i.e. divergent creativity tasks, than in combination tasks, i.e. convergent creativity tasks. The pattern of these results is consistent with the results of Oppezzo and Schwartz (2014).

The objective of our study was to deepen the understanding of this effect of movement on creativity by specifically isolating the visual perceptual component of movement through the use of virtual reality. In addition, virtual reality technologies have been shown to be effective for ideation (e.g. Yang et al., 2018; Feeman, Wright \& Salmon, 2018; Bourgeois-Bougrine et al., 2020). Although virtual reality is not a priori conducive to walking, it does allow us to create impressions of movement in the virtual environment. It is possible to create the illusion of movement by travelling through a virtual scene. To avoid the risks of motion sickness, the chosen scene in our experiment was a train cab with windows on each side, which allowed the scenery to move past the windows, giving the impression of moving forward without creating an inconsistency between the sensations of the body and perception. We hypothesize that in the study by Oppezzo and Schwartz (2014), the positive effect of the wheelchair on creativity comes from the fact that even without muscle activity, the brain receives visual information indicating that it is moving, and that this triggers cognitive effects relatively similar to those obtained by walking. This leads us to the hypothesis that in a virtual environment, participants may perform better when present in a moving environment (in our case a train) rather than a stationary one, even if they are physically not moving at the time.

\section{Method}

\section{Participants}

32 volunteers ( 26 men and 8 women) participated in the current study. The youngest was aged 14 years and the oldest 33 years. Their mean age was 22.1 years $(S D=2.98)$. All of them were students or interns involved in the field of virtual reality.

\section{Material and procedure}


Two creativity tests were used in this experiment: Guilford's Alternate Uses test (GAU) and the Remote Association Test (RAT). The GAU is a test of divergent creativity that consists of participants thinking of as many alternative uses of a given object as possible during a limited time period (Guilford, 1960). In our experiment, participants were given 5 minutes to think and speak out alternative uses of a common masonry brick. This test therefore leads to the collection of a set of ideas for each participant. Each set of ideas is then analyzed to be characterized on the basis of four criteria which constitute the scores. These scores for the GAU are originality (which evaluates whether the participant's ideas were unique when compared to other participants), fluency (the number of ideas generated), flexibility (the number of ideas belonging to different domains or categories) and elaboration (the amount of added detail given for each idea). The RAT is a test of convergent creativity where participants are presented with groups of three words, each of which is semantically related to a fourth word that participants must guess (Mednick, Mednick \& Mednick, 1964). The RAT scores then correspond to the number of words guessed by the participants.

Participants had to successively perform the GAU and the RAT aloud while immersed in a virtual environment using a HTC Vive headset. This virtual environment was that of the interior of an empty train car (see Figure 1).

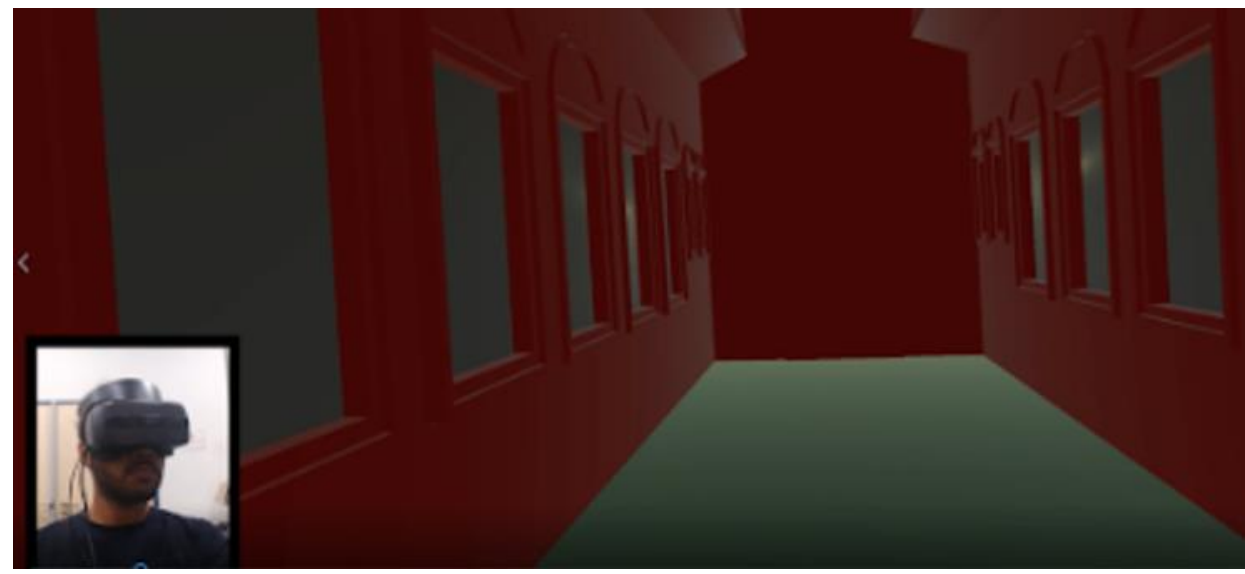

Figure 1. The experimental virtual environment from the participants' point of view

For 16 participants, the virtual environment was stationary, while for the remaining 16 participants, the train was moving, which was visually achieved by the moving of lights past the window (see Figure 2). In order to avoid any bias as a result of visual inspiration, no landscape was visible through the train's windows, as if the participants were in a tunnel. Thus, when the train was moving, the lights from inside the tunnel could be seen moving by. This train set was designed to represent a visual movement without movement of the user, while also avoiding motion sickness.
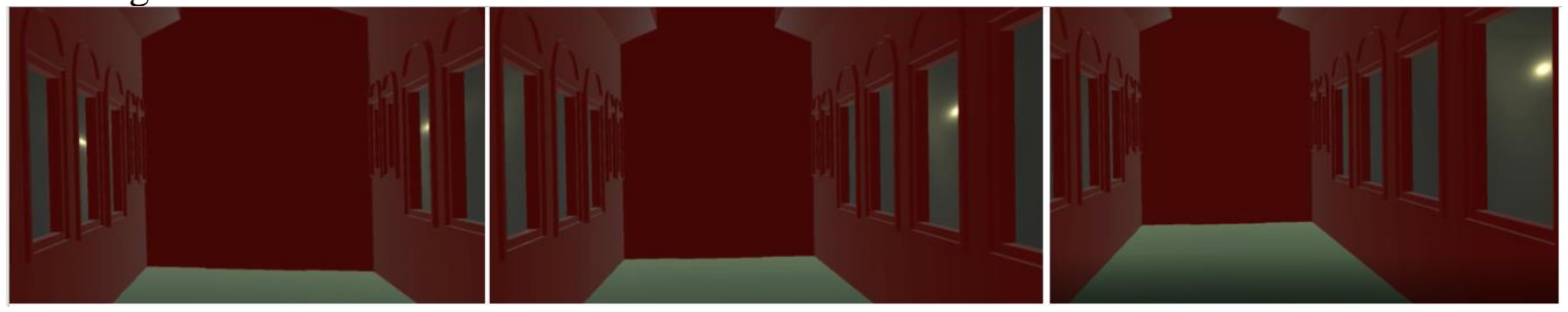

Figure 2. Three screeshots from the participants' point of view in the moving condition, with with the lights moving from front to back

\section{Results}


Table 1 shows the averages and standard deviations of the GAU and RAT sores under moving and non-moving conditions. We can see that empirically, the scores for all creativity criteria measured in the experiment are higher in the condition with movement than in the condition without movement. However, the significance of these differences needs to be assessed.

The homoscedasticity of the different variables has been tested using Levene tests. These tests revealed acceptable homoscedasticity for flexibility $(\mathrm{F}(1,29)=.348, \mathrm{p}=.560)$, fluency $(\mathrm{F}(1$, $29)=.714, p=.405)$, elaboration $(F(1,29)=.092, p=.763)$, originality $(F(1,29)=2.592, p=.1182)$ and convergence $(\mathrm{F}(1,29)=.249, \mathrm{p}=.621)$.

Table 1. Means and Standard Deviation (in brackets) for the four parameters of GAU and the scores of CRA

\begin{tabular}{|c|c|c|c|c|c|}
\hline & Originality & Fluency & Flexibility & Elaboration & RAT scores \\
\hline Without movement & $5.87(3.98)$ & $13.53(5.74)$ & $9.07(4.68)$ & 3.67 (3.66) & $6.07(2.28)$ \\
\hline With movement & $9.31(6.56)$ & $16.88(6.37)$ & $12.81(5.06)$ & $4.67(3.18)$ & $6.56(1.55)$ \\
\hline
\end{tabular}

All the comparisons of the means have been made by conducting T-tests. These tests did not reveal any significant differences for originality $(\mathrm{t}(29)=-1.781, \mathrm{p}=.087)$, fluency $(\mathrm{t}(29)=-1.536$, $\mathrm{p}=.135)$, elaboration $(\mathrm{t}(29)=-.827, \mathrm{p}=.415)$, or RAT scores $(\mathrm{t}(29)=-.703, \mathrm{p}=.489)$. Nevertheless, a significant difference was revealed for flexibility $(\mathrm{t}(29)=-2.140, \mathrm{p}=.041)$.

\section{Discussion}

The fact that that walking leads to an improvement in certain general cognitive performances (Aspinall, Mavros, Coyne \& Roe, 2015; Erickson et al., 2011; Keinänen, 2016; Kuo \& Yeh, 2016; Labonté-LeMoyne et al., 2015) and divergent creativity in particular (Oppezzo \& Schwartz, 2014), has been known for many years. This phenomenon of improved cognitive functioning related to walking is usually explained in terms of increased blood flow due to physical effort, which in turn has an impact on brain functioning (Ferris, Williams \& Shen, 2007; Hillman, Erickson \& Kramer, 2008). In the study by Oppezzo and Schwartz (2014), participants' divergent creativity was higher when pushed in a wheelchair than when they were immobile. This may suggest that being in motion, or more precisely perceiving oneself in motion, would be sufficient to generate an increase in creative performance. Thus, the objective of our study was to determine whether the perception of being in motion increases creativity, and more specifically to understand if the increase in creativity when walking is only due to physical activity or if there is also an additional effect of the visual perception of movement. The hypothesis was that participants immersed in a virtual reality train cab with a HMD would perform better in divergent creativity tasks when the train was moving than when it was stationary.

The results indicate that visual perception of movement does lead to a significant increase in performance on divergent creativity tasks. This difference concerns the criterion of flexibility, i.e. the range of ideas produced by participants. However, consistent with the study by Oppezzo and Schwartz (2014), the effect of visual movement on convergent creativity tasks is not significant. This pattern is also consistent with the results of Levy et al. (2013) revealing that the cerebellum is particularly engaged in divergent creativity, but less so for convergent one. These results suggest that in the case of walking, physical activity is only one factor that leads 
to the stimulation of cognitive functions, and the perception of movement might be another important factor.

A recent study has shown links between visual behaviour and divergent creativity (Kwon, Ryan, Bazylak \& Shu, 2020). However, these were based on different views of the images related to the GAU test. Participants were shown single or multi-angle images of objects for which they had to imagine alternative uses. In this case, the different angles of view may have resulted in different visual behaviours/perceptions, but also different forms of inspiration. This situation is not really comparable to our study in which the GAU was purely verbal, with no visual representation of the objects that were to be thought of.

Recommendations can still be drawn from these results. Many tools for making virtual reality meetings and conference calls have been developed in recent years. One could imagine that these tools may incorporate an option for virtual meeting environments to give the impression of travel in order to encourage the creativity of the participants involved. Brainstormings and brainwritings are common methods used in companies (Nutzmann, Sauer, Vob \& Bozkurt, 2019). It is possible to carry out electronic brainstormings which can for example be based on a 3D environment with avatars for each participant (Buisine \& Guegan, 2019) or on a digitized card game (Lo, Chiang \& Liang, 2013). These types of creativity workshops based on the use of a computer allow us to benefit from certain advantages, for example by manipulating social influence effects (Le Hénaff, Michinov \& Le Bohec, 2018). However, computers are rather designed to be used sitting down and therefore without physical movement. One can imagine integrating perceptual movement on the screen on the interface used for creativity.

The main limitation of our study concerns the measures of creativity used. Interpretations made on GAU scores representing divergent creativity and RAT scores representing convergent creativity should be considered with caution as these measures are not completely independent and pure (Patterson, Frith \& Loprinzi, 2018; Cortes, Weinberger, Daker \& Green, 2019). In order to remove doubts about the measures, further studies involving several different types of divergence and convergence oriented tasks should be carried out in order to have a better understanding of the effects involved.

Furthermore, we have chosen the speed at which the train travels arbitrarily, but we do not know at this stage whether this is the optimal speed to support creativity. Future research could be conducted to identify the effects of different speeds of motion on creativity. It is also possible that non-rectilinear movement may have an impact. Other forms of perceptual movement that can be easily integrated into an environment, such as a water fountain or a pendulum, could also be tested.

\section{Acknowledgement}

We thank the Time to Concept Chair for providing the necessary resources for this research.

\section{References}

Abdullah, S., Czerwinski, M., Mark, G., \& Johns, P. (2016, September). Shining (blue) light on creative ability. In Proceedings of the 2016 ACM International Joint Conference on Pervasive and Ubiquitous Computing (pp. 793-804). ACM.

Aspinall, P., Mavros, P., Coyne, R., \& Roe, J. (2015). The urban brain: analysing outdoor physical activity with mobile EEG. Br J Sports Med, 49(4), 272-276. 
Barron, F. (1963). Creativity and psychological health. Oxford, England : Van Nostrand.

Baumann, O., Borra, R. J., Bower, J. M., Cullen, K. E., Habas, C., Ivry, R. B., ... \& Paulin, M. G. (2015). Consensus paper: the role of the cerebellum in perceptual processes. The Cerebellum, 14(2), 197-220.

Bourgeois-Bougrine, S., Richard, P., Burkhardt, J. M., Frantz, B., \& Lubart, T. (2020). The expression of users' creative potential in virtual and real environments: An exploratory study. Creativity Research Journal, 1-11.

Brissenden, J. A., \& Somers, D. C. (2019). Cortico-cerebellar networks for visual attention and working memory. Current opinion in psychology.

Buisine, S., \& Guegan, J. (2019). Proteus vs. social identity effects on virtual brainstorming. Behaviour \& Information Technology, 1-13.

Cortes, R. A., Weinberger, A. B., Daker, R. J., \& Green, A. E. (2019). Re-examining prominent measures of divergent and convergent creativity. Current Opinion in Behavioral Sciences, 27, 90-93.

Erickson, K. I., Voss, M. W., Prakash, R. S., Basak, C., Szabo, A., Chaddock, L., ... \& Wojcicki, T. R. (2011). Exercise training increases size of hippocampus and improves memory. Proceedings of the National Academy of Sciences, 108(7), 3017-3022.

Feeman, S. M., Wright, L. B., \& Salmon, J. L. (2018). Exploration and evaluation of CAD modeling in virtual reality. Computer-Aided Design and Applications, 15(6), 892-904.

Ferris, L. T., Williams, J. S., \& Shen, C. L. (2007). The effect of acute exercise on serum brain-derived neurotrophic factor levels and cognitive function. Medicine \& Science in Sports \& Exercise, 39(4), 728-734.

Finch, L., Tomiyama, A., \& Ward, A. (2017). Taking a stand: the effects of standing desks on task performance and engagement. International journal of environmental research and public health, 14(8), 939.

Frith, E., \& Loprinzi, P. D. (2018). Experimental effects of acute exercise and music listening on cognitive creativity. Physiology \& behavior, 191, 21-28.

Gilson, N. D., Hall, C., Renton, A., Ng, N., \& von Hippel, W. (2017). Do sitting, standing, or treadmill desks impact psychobiological indicators of work productivity?. Journal of Physical Activity and Health, 14(10), 793-796.

Gondola, J. C. (1986). The enhancement of creativity through long- and short-term exercise programs. Journal of Social Behavior \& Personality, 1, 77-82.

Gondola, J. C. (1987). The effects of a single bout of aerobic dancing on selected tests of creativity. Journal of Social Behavior \& Personality, 2, 275-278.

Guilford, J. P. (1960). Alternate uses. Form A. Berverly Hills, CA : Sheridan Supply.

Hillman, C. H., Erickson, K. I., \& Kramer, A. F. (2008). Be smart, exercise your heart: exercise effects on brain and cognition. Nature reviews neuroscience, 9(1), 58-65. 
Kwon, E., Ryan, J. D., Bazylak, A., \& Shu, L. H. (2020). Does Visual Fixation Affect Idea Fixation?. Journal of Mechanical Design, 142(3).

Labonté-LeMoyne, É., Santhanam, R., Léger, P. M., Courtemanche, F., Fredette, M., \& Sénécal, S. (2015). The delayed effect of treadmill desk usage on recall and attention. Computers in Human Behavior, 46, 1-5.

Mednick, M. T., Mednick, S. A., \& Mednick, E. V. (1964). Incubation of creative performance and specific associative priming. The Journal of Abnormal and Social Psychology, 69(1), 84.

Nutzmann, M., Sauer, T., VOß, M., \& Bozkurt, H. (2019). Study on learning concepts applying creativity methods in education and industry. In DS 95: Proceedings of the 21 st International Conference on Engineering and Product Design Education (E\&PDE 2019), University of Strathclyde, Glasgow. 12th-13th September 2019.

Keinänen, M. (2016). Taking your mind for a walk: a qualitative investigation of walking and thinking among nine Norwegian academics. Higher Education, 71(4), 593-605.

Knight, A. P., \& Baer, M. (2014). Get up, stand up: The effects of a non-sedentary workspace on information elaboration and group performance. Social Psychological and Personality Science, 5(8), 910-917.

Kuo, C. Y., \& Yeh, Y. Y. (2016). Sensorimotor-conceptual integration in free walking enhances divergent thinking for young and older adults. Frontiers in psychology, 7, 1580.

Küper, M., Kaschani, P., Thürling, M., Stefanescu, M. R., Burciu, R. G., Göricke, S., ... \& Timmann, D. (2016). Cerebellar fMRI activation increases with increasing working memory demands. The Cerebellum, 15(3), 322-335.

Le Hénaff, B., Michinov, N., \& Le Bohec, O. (2018). Applying the SIDE model to brainwriting: The impact of intergroup comparison and anonymity on creative performance. Journal of Applied Social Psychology, 48(7), 351-359.

Levy, R., Urbanski, M., Josse, G., \& Volle, E. (2013). Rostral and caudal prefrontal contribution to creativity: A meta-analysis of functional imaging data. Frontiers in Human Neuroscience.

Lo, L. J., Chiang, C. D., \& Liang, R. H. (2013). HexDeck: Gamification of Tangibles for Brainstorming. Consilence and Innovation in Design-In Procs. of the 5th IASDR, 3165-3175.

Nawrot, M., \& Rizzo, M. (1995). Motion perception deficits from midline cerebellar lesions in human. Vision research, 35(5), 723-731.

O'Mara, S. M. (2019). In Praise of Walking: The New Science of how We Walk and why It's Good for Us. Bodley Head.

Oppezzo, M., \& Schartz, D-L. (2014). Give Your Ideas Some Legs : The Positive Effect of Walking on Creative Thinking. Journal of Experimental Psychology : Learning, Memory, and Cognition. 40(4), 1142-1152. 
Patterson, R., Frith, E., \& Loprinzi, P. D. (2018). The experimental effects of acute walking on cognitive creativity performance. Journal of behavioral health, 7(3), 113$11910.5455 /$ jbh.20180415053930

Salmon, P. (2001). Effects of physical exercise on anxiety, depression, and sensitivity to stress: a unifying theory. Clinical psychology review, 21(1), 33-61.

Schaefer, S., Lövdén, M., Wieckhorst, B., \& Lindenberger, U. (2010). Cognitive performance is improved while walking: Differences in cognitive-sensorimotor couplings between children and young adults. European Journal of Developmental Psychology, 7(3), 371-389.

Srygley, J. M., Mirelman, A., Herman, T., Giladi, N., \& Hausdorff, J. M. (2009). When does walking alter thinking? Age and task associated findings. Brain research, 1253, 92-99.

Weuve, J., Kang, J. H., Manson, J. E., Breteler, M. M., Ware, J. H., \& Grodstein, F. (2004). Physical activity, including walking, and cognitive function in older women. Jama, 292(12), 1454-1461.

Yang, X., Lin, L., Cheng, P. Y., Yang, X., Ren, Y., \& Huang, Y. M. (2018). Examining creativity through a virtual reality support system. Educational Technology Research and Development, 66(5), 1231-1254.

Zhou, Y., Zhang, Y., Hommel, B., \& Zhang, H. (2017). The impact of bodily states on divergent thinking: evidence for a control-depletion account. Frontiers in psychology, 8 , 1546. 